\title{
Polymorphisms in the SOCS7 gene and glucose homeostasis traits
}

\author{
Melissa M Capuano ${ }^{1}$, John D Sorkin ${ }^{2,3,4}$, Yen-Pei C Chang ${ }^{1}$, Hua Ling ${ }^{1}$, Jeffrey R O'Connell ${ }^{1}$, Paul B Rothman ${ }^{5}$, \\ Braxton D Mitchell ${ }^{1}$ and Kristi D Silver ${ }^{1,4^{*}}$
}

\begin{abstract}
Background: SOCS7 is a member of the suppressor of cytokine signaling family of proteins and is expressed in skeletal muscle and islets. SOCS7 deficient mice develop islet hyperplasia in the setting of increased insulin sensitivity and normal glucose tolerance. The objective of this study was to determine if variants in SOCS7 play a role in variation of glucose and insulin levels and the development of type 2 diabetes (T2DM).

Results: Five SOCS7 tagging SNPs were genotyped in diabetic and nondiabetic Old Order Amish. A case-control study was performed in T2DM $(n=145)$ and normal glucose tolerant $(n=358)$ subjects. Nominal associations were observed with T2DM and the minor alleles for rs8068600 ( $P=0.01)$ and rs8074124 ( $P=0.04)$; however, only rs8068600 remained significant after Bonferroni adjustment for multiple comparisons ( $P=0.01)$. Among nondiabetic Amish ( $n=765)$, no significant associations with glucose or insulin traits including fasting or 2 hour glucose and insulin from the oral glucose tolerance test, insulin or glucose area under the curve, Matsuda Index or HOMA-IR were found for any of the SNPS.

Conclusion: In conclusion, genetic variants in the SOCS7 gene do not impact variation in glucose homeostasis traits and only minimally impact risk of T2DM in the Old Order Amish. Our study was not able to address whether rare variants that potentially impact gene function might influence T2DM risk.
\end{abstract}

Keywords: Type 2 diabetes, Genetics, SOCS7 gene, Polymorphism

\section{Background}

The suppressor of cytokine signaling (SOCS) proteins are a family of eight proteins that negatively regulate cytokine signaling pathways via inhibition of JAK/STAT signal transduction [1-3]. Expression of SOCS proteins is induced by proinflammatory cytokines including IL1beta, INF-gamma, TNF-alpha, IL-6 and growth hormone [4-7]. In animal models, SOCS proteins 1 and 3 have been shown to play a role in insulin signaling and diabetes [7-14]; however, less is known about other members of the SOCS family and their role in the development of diabetes. In C57BL/6J mice, SOCS7 is expressed at highest levels in skeletal muscle, pancreatic

\footnotetext{
* Correspondence: ksilver@medicine.umaryland.edu

1 Division of Endocrinology, Diabetes, and Nutrition, University of Maryland School of Medicine, 660 West Redwood Street, Room 494, Baltimore, MD 21201, USA

${ }^{4}$ Baltimore Geriatric Research, Education and Clinical Center, Baltimore, MD, USA

Full list of author information is available at the end of the article
}

islets, and brain [15]. SOCS7 deficient mice develop islet hyperplasia $[15,16]$ and on a mixed C57BL/6J and 129S6/SvEvTac background also experience increased insulin sensitivity as demonstrated by lower glucose levels and prolonged hypoglycemia during an insulin tolerance test, and increased glucose clearance during an intraperitoneal glucose tolerance test [15]. These data suggest that SOCS7 plays a role in regulating glucose homeostasis. A proposed molecular mechanism for this regulation is through SOCS7 targeting of insulin receptor substrate (IRS) proteins for ubiquitination and proteasomal degradation. This action would decrease insulin signaling, and thereby, increase insulin resistance. Decreased insulin signaling via decreased IRS levels has also been proposed as the mechanism whereby SOCS7 affects islet size [15].

The SOCS7 gene contains 10 exons over a $45 \mathrm{~kb}$ region on human chromosome 17q12. In humans, SOCS7 is expressed diffusely with high levels in testis, ovaries, spleen, brain and spinal cord and moderate levels in
C Biomed Central

(c) 2013 Capuano et al.; licensee BioMed Central Ltd. This is an Open Access article distributed under the terms of the Creative Commons Attribution License (http://creativecommons.org/licenses/by/2.0), which permits unrestricted use, distribution, and reproduction in any medium, provided the original work is properly cited. 
pancreatic islets (http://www.genecards.org). As a result of SOCS7's role in glucose homeostasis in mice, we hypothesized that variants in SOCS7 might contribute to variation in glucose and insulin levels as well as the development of Type 2 diabetes (T2DM) in humans. To test this hypothesis, we genotyped a panel of tagging SNPs in the SOCS7 gene in the Old Order Amish of Lancaster, Pennsylvania and assessed associations with T2DM and insulin and glucose related traits.

\section{Methods}

\section{Old Order Amish of Lancaster Pennsylvania}

The Old Order Amish are a genetically well-defined Caucasian founder population. Nearly all of these individuals share common ancestors insofar as the entire Amish community of Lancaster County (now numbering over 30,000 individuals) can be connected into a single 14-generation pedigree [17].

The Amish Family Diabetes Study (AFDS) was initiated in 1995 with the goal of identifying susceptibility genes for T2DM and related traits. A description of subject recruitment and the examination protocol has been previously reported [18]. Briefly, probands with T2DM and their extended family members were invited to participate in the study. After an overnight fast, a 75 gram oral glucose tolerance test (OGTT) was administered to all subjects without a prior history of diabetes. Blood samples were sent for analysis of glucose and insulin concentrations. Glucose concentrations were assayed with a Beckman glucose analyzer (Beckman Coulter, Fullerton, CA) using the glucose oxidase method (interassay coefficient of variation $=1.52 \%$ ). Insulin levels were determined by radioimmunoassay (Linco, St. Louis, MO) (interassay coefficient of variation $=4.42 \%$ ).

Criteria for the diagnosis of diabetes were adapted from American Diabetes Association 1997 recommendations [19]. Diabetes status was defined by a single fasting venous plasma glucose level $\geq 7 \mathrm{mmol} / \mathrm{l}$, a 2 hour OGTT venous plasma glucose level $\geq 11.1 \mathrm{mmol} / \mathrm{l}$, current treatment with insulin and/or oral hypoglycemic agents, or by confirmed diagnosis by a physician. Impaired glucose tolerance (IGT) status was defined as a 2 hour OGTT glucose value between 7.8 and $11.1 \mathrm{mmol} / \mathrm{L}$. Normal glucose tolerance (NGT) was defined as having a fasting glucose $<6.1 \mathrm{mmol} / \mathrm{L}$ and a 2 hour OGTT glucose $<7.8 \mathrm{mmol} / \mathrm{L}$. Diabetic subjects with an age at diagnosis $<35$ years were reclassified as diabetes status unknown in order to minimize heterogeneity due to inclusion of subjects with type 1 diabetes. For the case-control study, a total of 503 Amish subjects [T2DM $(n=145)$, and NGT $(n=358)$ aged 38 years or older] from the Amish Family Diabetes Study (AFDS) were included in the analysis (Table 1).
Table 1 Clinical characteristics of the Amish*

\begin{tabular}{|c|c|c|c|}
\hline Trait & $\begin{array}{c}\text { T2DM } \\
(n=145)\end{array}$ & $\begin{array}{c}\text { NGT } \\
(n=358)\end{array}$ & $\begin{array}{c}\text { NGT + IGT } \\
(n=765)\end{array}$ \\
\hline$\%$ female & 69.7 & 48.0 & 52.6 \\
\hline Age (yrs) & $65 \pm 12$ & $51 \pm 11$ & $44.3 \pm 14.7$ \\
\hline $\mathrm{BMI}\left(\mathrm{kg} / \mathrm{m}^{2}\right)$ & $30.1 \pm 4.0$ & $27.4 \pm 4.7$ & $27.0 \pm 4.8$ \\
\hline$\%$ IGT & - & - & 19.1 \\
\hline $\begin{array}{l}\text { Age of onset } \\
\text { of DM (yrs) }\end{array}$ & $59 \pm 11$ & - & - \\
\hline HOMA-IR & - & $2.5 \pm 1.5$ & $2.5 \pm 1.4$ \\
\hline $\begin{array}{l}\text { Fasting Glucose } \\
\text { (mmol/L) }\end{array}$ & - & $5.04 \pm 0.42$ & $5.02 \pm 0.46$ \\
\hline $\begin{array}{l}2 \text { hour Glucose } \\
\text { ( } \mathrm{mmol} / \mathrm{L})\end{array}$ & - & $5.76 \pm 1.20$ & $6.21 \pm 1.7$ \\
\hline $\begin{array}{l}\text { Fasting Insulin }{ }^{\dagger} \\
(\mathrm{pmol} / \mathrm{L})\end{array}$ & - & $68.1(55.6,86.8)$ & $66.7(54.9,86.1)$ \\
\hline $\begin{array}{l}2 \text { hour Insulin }^{+} \\
(\mathrm{pmol} / \mathrm{L})\end{array}$ & - & $211.8(126.4,341.0)$ & $218.8(128.5,364.6)$ \\
\hline $\begin{array}{l}\text { AUC Glucose } \\
(\mathrm{mmol} / \mathrm{L})\end{array}$ & - & $349.2 \pm 51.5$ & $359.9 \pm 67.2$ \\
\hline $\begin{array}{l}\text { AUC Insulin }^{+} \\
(\mathrm{pmol} / \mathrm{L})\end{array}$ & - & $761.9(540.3,1046.6)$ & $752.1(525.0,1046.6)$ \\
\hline
\end{tabular}

* mean \pm SD unless otherwise indicated.

${ }^{\dagger}$ median (25th, 75th percentile).

Association studies with glucose homeostasis measures including fasting glucose, fasting insulin, 2 hour glucose, 2 hour insulin, area under the curve (AUC) glucose, AUC insulin, HOMA-IR and Matsuda Index were performed in a larger sample of 765 nondiabetic Amish subjects that included the 358 NGT subjects described above, an additional 218 NGT subjects, and 148 IGT subjects. Area under the curve was calculated using the trapezoid rule. Homeostasis model assessment of insulin resistance (HOMA-IR) was calculated according to the following formula: HOMA-IR $=$ [fasting serum insulin $(\mathrm{mU} / \mathrm{L}) \mathrm{x}$ fasting plasma glucose $(\mathrm{mmol} / \mathrm{L})] / 22.5$ [20] The Matsuda Index was calculated to assess insulin resistance [21].

All study protocols were approved by the Institutional Review Board at the University of Maryland School of Medicine. Informed consent was obtained from each study participant prior to enrollment.

\section{Genotyping}

DNA was extracted from leukocytes for genotyping. We selected 5 SNPs (from a total of 36 SNPs represented in HapMap CEU) that tagged SOCS7 and the $5 \mathrm{~kb}$ region upstream and downstream of the gene. These SNPs captured $100 \%$ of common variants $(>5 \%)$ in HapMap CEU in the SOCS7 gene at $r^{2}>0.95$ (HapMap Release 36). Figure 1 shows the locations of these SNPs relative to the 10 exons and their LD structure. Rs3890580 was genotyped by pyrosequencing (PSQ HS 96MA System; 


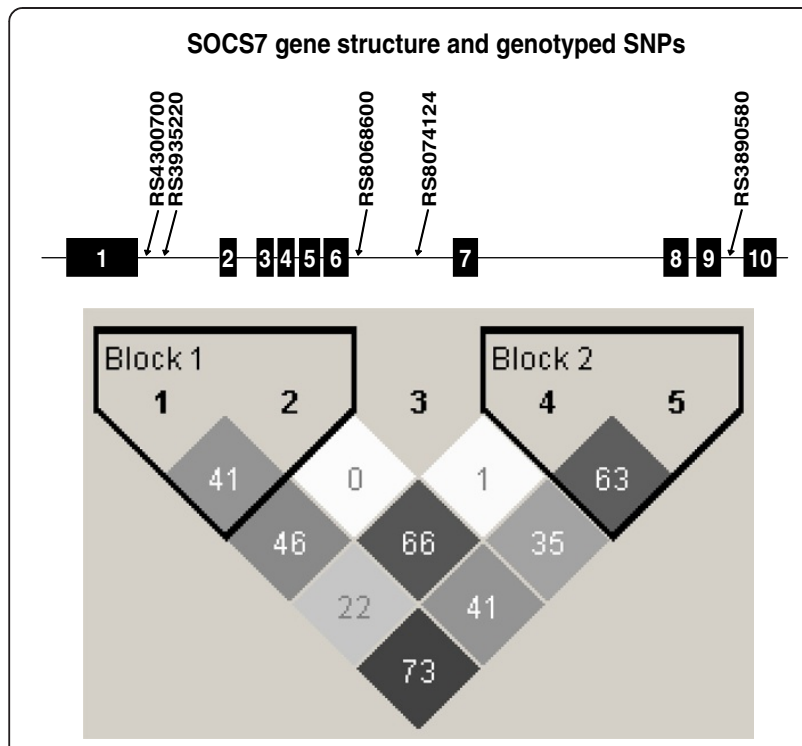

Figure 1 SOCS7 gene structure and genotyped SNPs. The 5 SNPS are represented by the numbers 1-5 above the correlation matrix. The numbers within each box of the correlation matrix represent pairwise $r^{2}$ value between SNPs.

Pyrosequencing $\mathrm{AB}$, Uppsala, Sweden) according to the manufacturer's protocol. Rs4300700 was genotyped using either TaqMan SNP Genotyping Assays (Applied Biosystems; Foster City, CA) according to the manufacturer's protocol or by dideoxy sequencing on an $\mathrm{ABI}$ 3730xl sequencer. Rs3935220, rs8068600 and rs8074124 were genotyped by either pyrosequencing or TaqMan. At least 5\% duplicate samples were included to determine genotype concordance rates within the same platform and between different genotyping platforms, which were $95-100 \%$. Discordant samples were excluded from analysis.

Genome wide association study (GWAS) SOCS7 SNP association data was downloaded from the MetaAnalyses of Glucose and Insulin-related traits Consortium (MAGIC) web site (http://www.magicinvestigators. org/downloads/) for HOMA-IR, fasting insulin, fasting glucose and 2 hour glucose [22,23]. The National Human Genome Research Institute (NHGRI) database (www.genome.gov/gwastudies) was used to search for
SOCS7 SNPs associated with T2DM as well as glucose and insulin related traits [24].

\section{Statistical analysis}

Before analysis, Amish genotypes were checked for Mendelian consistency using the PedCheck software program [25] in the extended Amish pedigree. A small number of Mendelian errors ( $<1.5 \%$ of genotypes) were either resolved or removed before analysis. Observed genotypes for all SNPs were tested for fit with those expected under Hardy-Weinberg equilibrium using the Chi square test; all genotype distributions conformed to Hardy-Weinberg expectations.

Quantitative trait means were estimated according to SOCS7 genotypes in the 765 nondiabetic Amish subjects. To account for the relatedness among family members, the measured genotype approach was used [26] in which we estimated the likelihood of specific genetic models given the pedigree structure. Parameter estimates were obtained by maximum likelihood methods, and the significance of association was tested by likelihood ratio tests. Analyses were performed using recessive, dominant and additive models. Within each model, we simultaneously estimated the effects of age and sex, and age, sex and body mass index (BMI). Quantitative trait analyses were conducted using the SOLAR software program [27]. To account for the multiple SNPs tested, we considered a P-value of 0.01 to be statistically significant. Analysis of the diabetes trait was made using the dichotomous trait extension to the SOLAR software program, which employs a threshold model to assess the effect of genotype on the binary outcome.

\section{Results}

Characteristics of the Amish subjects are presented in Table 1. To determine if SNPs in the SOC7 gene contribute to the development of T2DM, we employed a case-control analysis utilizing 145 T2DM cases and 358 NGT controls from the AFDS. Subjects with T2DM were older, had a higher BMI and were more likely to be female. Nominal associations with T2DM were found for the minor allele for rs8068600 $(P=0.01)$ and $r s 8074124$ $(\mathrm{P}=0.04)$ (Table 2, Additional file 1: Table S1); however,

Table 2 Allele frequencies and results of association analysis

\begin{tabular}{|c|c|c|c|c|c|c|c|c|}
\hline \multirow[t]{2}{*}{ SNP name } & \multirow[t]{2}{*}{ Major/minor allele } & \multirow[t]{2}{*}{ Minor allele frequency } & \multicolumn{2}{|c|}{ Matsuda index } & \multicolumn{2}{|c|}{ Fasting glucose } & \multicolumn{2}{|c|}{ Diabetes vs. control } \\
\hline & & & $P$ value & $\beta$ coefficient & $P$ value & $\beta$ coefficient & $P$ value & Odds ratio \\
\hline rs4300700 & $G / A$ & 0.08 & 0.98 & -0.006 & 0.96 & 0.043 & 0.84 & 0.96 \\
\hline rs3935220 & $\mathrm{G} / \mathrm{C}$ & 0.09 & 0.31 & 0.227 & 0.26 & -0.887 & 0.99 & 1.00 \\
\hline rs8068600 & $\mathrm{G} / \mathrm{C}$ & 0.17 & 0.25 & 0.236 & 0.98 & -0.021 & 0.01 & 1.59 \\
\hline rs8074124 & $\mathrm{T} / \mathrm{C}$ & 0.22 & 0.46 & 0.133 & 0.40 & -0.524 & 0.04 & 1.39 \\
\hline rs3890580 & $\mathrm{T} / \mathrm{A}$ & 0.20 & 0.45 & 0.144 & 0.19 & -0.864 & 0.15 & 1.27 \\
\hline
\end{tabular}


after adjustment for multiple comparisons, only rs8068600 met the Bonferroni-adjusted threshold for statistical significance $(\mathrm{P}=0.01)$. No significant or nominally significant $(\mathrm{P}<0.05)$ associations with glucose or insulin traits including fasting or 2 hour glucose and insulin from the OGTT, Insulin AUC, Glucose AUC, Matsuda Index or HOMA-IR were found for any of the SNPs in the Amish after adjustment for age and sex. Similar results were found when BMI was included in the model. Data from the MAGIC GWAS identified a nominal association of rs4300700 with ln fasting insulin $(P=0.01)$. No additional associations were found in the MAGIC data for SOCS7 tagging SNPs for ln fasting insulin, fasting glucose, 2 hour glucose or HOMA-IR [22,23]. Review of the NHGRI GWAS database did not reveal any SOCS7 SNP associations with T2DM or other glucose homeostasis traits; however, SNPs included in the database are limited to those with P-values $<1.0 \times 10^{-5}[24]$.

Linkage disequilibrium (LD) analysis in the Amish revealed some LD among most of the SOCS7 SNPs $\left(\mathrm{r}^{2}=0\right.$ 0.73 ; see Figure 1). The closest genes $5^{\prime}$ of SOCS7 are GPR179 $(8.3 \mathrm{~kb})$ and MRPL45 $(28.9 \mathrm{~kb})$ and the closest gene $3^{\prime}$ is SNIP (178.3 kb). None of these genes are in the same LD block as the SOCS7 gene.

\section{Discussion and conclusion}

Based on studies in mice and other members of the SOCS family of proteins, SOCS7 is an excellent candidate gene for regulation of glucose homeostasis traits and T2DM as a mutation in the SOCS7 gene causing decreased or absent function of the SOCS7 protein would be expected to improve insulin sensitivity and decrease the risk of T2DM while an activating mutation in the SOCS7 gene would be expected to increase insulin resistance and the risk of T2DM [12,14,15,28,29]. Despite genotyping SNPs in and adjacent to the SOCS7 gene, SNP genotype did not significantly impact risk of T2DM, measures of insulin resistance or glucose levels after adjustment for multiple comparisons. These results are consistent with findings in MAGIC and other GWAS [22-24]. Only one other candidate gene study has examined the role of genetic variation in the SOCS7 gene with measures of insulin resistance. In contrast to our study, Tellechea et al. found an association between rs8074124 and HOMA-IR $(\mathrm{P}=0.018)$ in 780 men with European ancestry seen at the University of Buenos Aires [30]. Differences in results may be due to the inclusion of women in our study as well as differences in recruitment strategies as the University of Buenos Aires population was recruited from the Department of Haemotherapy.

While the number of subjects included in our study was relatively small compared to those found in genome wide association studies, our sample of 765 subjects did none-the-less provide $80 \%$ power to detect an association that accounted for as little as $1.5 \%$ of the total variance in glucose and insulin homeostasis traits. One limitation of our study is that we were underpowered to detect modest effect sizes for T2DM in the case-control study as our sample provided $80 \%$ power to detect odds ratios of 1.6 to 1.8. While it is possible that SOCS7 plays a role in T2DM and related glucose homeostasis traits in other populations, this scenario seems unlikely as many genetic findings in the Amish are similar to those found in the outbreed Caucasian population [31-33]. Furthermore, in SOCS7 SNPs found on the DNA microarray chips used for T2DM and glucose homeostasis GWAS, no significant associations have been reported with these SNPs or other SNPs in the region of the SOCS7 gene. Additionally, in studies by MAGIC, only one nominally associated SNP (rs4300700) was identified which is consistent with our findings in the Amish of a very limited to no impact of SOCS7 on risk of T2DM or variation in glucose homeostasis traits [22]. Another limitation of our study is the higher number of female subjects in the T2DM group compared to the NGT and NGT + IGT groups. This difference may be due to selection bias related possibly to women being more health conscious and more willing to take advantage of the screening done as part of the study.

In summary, genetic variation in the SOCS7 gene does not significantly impact glucose homeostasis traits or risk of T2DM in the Old Order Amish of Lancaster Pennsylvania.

\section{Additional file}

Additional file 1: Table S1. Genotype Frequency of SOCS7 SNPS.

\section{Abbreviations}

AIRg: Acute insulin response to glucose; AUC: Area under the curve; AFDS: Amish Family Diabetes Study; BMI: Body mass index; GWAS: Genome wide association study; HOMA-IR: Homeostasis model assessment of insulin resistance; IFG: Impaired fasting glucose; IGT: Impaired glucose tolerance; IRS: Insulin receptor substrate; LD: Linkage disequilibrium; MAGIC: MetaAnalyses of Glucose and Insulin-related traits Consortium; NHGRI: National Human Genome Research Institute; NGT: Normal glucose tolerance; OGTT: Oral glucose tolerance test; SNP: Single nucleotide polymorphism; SOCS: Suppressor of cytokine signaling; T2DM: Type 2 diabetes.

\section{Competing interests}

The authors have no competing interests to declare.

\section{Authors' contributions}

Conceived and designed the experiments: MMC. KDS, PBR; Performed the experiments: MMC, KDS; Analyzed the data: MMC, KDS, BDM, JRO, JDS. HL, YPCC; Wrote the paper: MMC, KDS, BDM; Reviewed Manuscript MMC, PBR, BDM, KDS, JDS. All authors read and approved the final manuscript. 


\section{Acknowledgements}

This work was supported by NIH research grants R01 DK54261, R01 DK67231 and R01 DK68495, American Diabetes Association grant 1-08-CR-60, University of Maryland General Clinical Research Center (M01 RR16500), Baltimore Diabetes Research and Training Center (P60 DK079637), Hopkins Bayview General Clinical Research Center (M01 RR02719), Maryland Clinical Nutrition Research Unit (P30 DK072488), Baltimore Veterans Administration Geriatric Research and Education Clinical Center, and Claude D. Pepper Older Americans Independence Center (5P 30 AG028747-02). We thank Xiao Chun Wang and Kathy Ryan for excellent technical and analytic assistance, and Dr. Alan Shuldiner and the Amish Research Clinic Staff for their energetic efforts in study subject recruitment and characterization. This study would not have been possible without the extraordinary cooperation and support of the Amish community. Data on glycemic traits have been contributed by MAGIC investigators and have been downloaded from www.magicinvestigators.org.

\section{Author details}

${ }^{1}$ Division of Endocrinology, Diabetes, and Nutrition, University of Maryland School of Medicine, 660 West Redwood Street, Room 494, Baltimore, MD 21201, USA. ${ }^{2}$ Division of Gerontology, University of Maryland School of Medicine, Baltimore, MD, USA. ${ }^{3}$ Division of Geriatrics and Gerontology, Department of Medicine, Department of Veterans Affairs, Veterans Affairs Medical Center, Baltimore, MD, USA. ${ }^{4}$ Baltimore Geriatric Research, Education and Clinical Center, Baltimore, MD, USA. ${ }^{5}$ Department of Internal Medicine, University of lowa, lowa City, IA, USA.

Received: 22 February 2013 Accepted: 7 June 2013

Published: 15 June 2013

\section{References}

1. Endo TA, Masuhara M, Yokouchi M, Suzuki R, Sakamoto H, Mitsui K, Matsumoto A, Tanimura S, Ohtsubo M, Misawa H, et al: A new protein containing an SH2 domain that inhibits JAK kinases. Nature 1997, 387(6636):921-924.

2. Naka T, Narazaki M, Hirata M, Matsumoto T, Minamoto S, Aono A, Nishimoto $N$, Kajita T, Taga T, Yoshizaki K, et al: Structure and function of a new STAT-induced STAT inhibitor. Nature 1997, 387(6636):924-929.

3. Starr R, Willson TA, Viney EM, Murray LJ, Rayner JR, Jenkins BJ, Gonda TJ, Alexander WS, Metcalf D, Nicola NA, et al: A family of cytokine-inducible inhibitors of signalling. Nature 1997, 387(6636):917-921.

4. Chong MM, Thomas HE, Kay TW: Gamma-Interferon signaling in pancreatic beta-cells is persistent but can be terminated by overexpression of suppressor of cytokine signaling-1. Diabetes 2001, 50(12):2744-2751.

5. Fasshauer M, Kralisch S, Klier M, Lossner U, Bluher M, Klein J, Paschke R: Insulin resistance-inducing cytokines differentially regulate SOCS mRNA expression via growth factor- and Jak/Stat-signaling pathways in 3T3-L1 adipocytes. J Endocrinol 2004, 181(1):129-138.

6. Santangelo C, Scipioni A, Marselli L, Marchetti P, Dotta F: Suppressor of cytokine signaling gene expression in human pancreatic islets: modulation by cytokines. Eur J Endocrinol 2005, 152(3):485-489.

7. Shi H, Cave B, Inouye K, Bjorbaek C, Flier JS: Overexpression of suppressor of cytokine signaling 3 in adipose tissue causes local but not systemic insulin resistance. Diabetes 2006, 55(3):699-707.

8. Emanuelli B, Peraldi P, Filloux C, Chavey C, Freidinger K, Hilton DJ, Hotamisligil GS, Van Obberghen E: SOCS-3 inhibits insulin signaling and is up-regulated in response to tumor necrosis factor-alpha in the adipose tissue of obese mice. J Biol Chem 2001, 276(51):47944-47949.

9. Jamieson E, Chong MM, Steinberg GR, Jovanovska V, Fam BC, Bullen DV, Chen Y, Kemp BE, Proietto J, Kay TW, et al: Socs1 deficiency enhances hepatic insulin signaling. J Biol Chem 2005, 280(36):31516-31521.

10. Rieusset J, Bouzakri K, Chevillotte E, Ricard N, Jacquet D, Bastard JP, Laville $M$, Vidal H: Suppressor of cytokine signaling 3 expression and insulin resistance in skeletal muscle of obese and type 2 diabetic patients. Diabetes 2004, 53(9):2232-2241.

11. Ronn SG, Billestrup N, Mandrup-Poulsen T: Diabetes and suppressors of cytokine signaling proteins. Diabetes 2007, 56(2):541-548.

12. Rui L, Yuan M, Frantz D, Shoelson S, White MF: SOCS-1 and SOCS-3 block insulin signaling by ubiquitin-mediated degradation of IRS1 and IRS2. J Biol Chem 2002, 277(44):42394-42398.
13. Shi H, Tzameli I, Bjorbaek C, Flier JS: Suppressor of cytokine signaling 3 is a physiological regulator of adipocyte insulin signaling. J Biol Chem 2004, 279(33):34733-34740.

14. Ueki K, Kondo T, Kahn CR: Suppressor of cytokine signaling 1 (SOCS-1) and SOCS-3 cause insulin resistance through inhibition of tyrosine phosphorylation of insulin receptor substrate proteins by discrete mechanisms. Mol Cell Biol 2004, 24(12):5434-5446.

15. Banks AS, Li J, McKeag L, Hribal ML, Kashiwada M, Accili D, Rothman PB: Deletion of SOCS7 leads to enhanced insulin action and enlarged islets of Langerhans. J Clin Invest 2005, 115(9):2462-2471.

16. Krebs DL, Metcalf D, Merson TD, Voss AK, Thomas T, Zhang JG, Rakar S, O'Bryan MK, Willson TA, Viney EM, et al: Development of hydrocephalus in mice lacking SOCS7. Proc Natl Acad Sci USA 2004, 101(43):15446-15451.

17. Agarwala R, Biesecker LG, Hopkins KA, Francomano CA, Schaffer AA: Software for constructing and verifying pedigrees within large genealogies and an application to the Old Order Amish of Lancaster County. Genome Res 1998, 8(3):211-221.

18. Hsueh WC, Mitchell BD, Aburomia R, Pollin T, Sakul H, Gelder Ehm M, Michelsen BK, Wagner MJ, St Jean PL, Knowler WC, et al: Diabetes in the Old Order Amish: characterization and heritability analysis of the Amish Family Diabetes Study. Diabetes Care 2000, 23(5):595-601.

19. Report of the expert committee on the diagnosis and classification of diabetes mellitus. Diabetes Care 1997, 20(7):1183-1197.

20. Bonora E, Targher G, Alberiche M, Bonadonna RC, Saggiani F, Zenere MB, Monauni T, Muggeo M: Homeostasis model assessment closely mirrors the glucose clamp technique in the assessment of insulin sensitivity: studies in subjects with various degrees of glucose tolerance and insulin sensitivity. Diabetes Care 2000, 23(1):57-63.

21. Matsuda M, DeFronzo RA: Insulin sensitivity indices obtained from oral glucose tolerance testing: comparison with the euglycemic insulin clamp. Diabetes Care 1999, 22(9):1462-1470.

22. Dupuis J, Langenberg C, Prokopenko I, Saxena R, Soranzo N, Jackson AU, Wheeler E, Glazer NL, Bouatia-Naji N, Gloyn AL, et al: New genetic loci implicated in fasting glucose homeostasis and their impact on type 2 diabetes risk. Nat Genet 2010, 42(2):105-116.

23. Saxena R, Hivert MF, Langenberg C, Tanaka T, Pankow JS, Vollenweider $P$, Lyssenko V, Bouatia-Naji N, Dupuis J, Jackson AU, et al: Genetic variation in GIPR influences the glucose and insulin responses to an oral glucose challenge. Nat Genet 2010, 42(2):142-148.

24. Hindorff LA, Sethupathy P, Junkins HA, Ramos EM, Mehta JP, Collins FS, Manolio TA: Potential etiologic and functional implications of genomewide association loci for human diseases and traits. Proc Natl Acad Sci USA 2009, 106(23):9362-9367.

25. O'Connell JR, Weeks DE: PedCheck: a program for identification of genotype incompatibilities in linkage analysis. Am J Hum Genet 1998, 63(1):259-266.

26. Boerwinkle $E$, Chakraborty R, Sing CF: The use of measured genotype information in the analysis of quantitative phenotypes in man. I. Models and analytical methods. Ann Hum Genet 1986, 50(Pt 2):181-194.

27. Almasy L, Blangero J: Multipoint quantitative-trait linkage analysis in general pedigrees. Am J Hum Genet 1998, 62(5):1198-1211.

28. Liao L, Zheng R, Wang C, Gao J, Ying Y, Ning Q, Luo X: The influence of down-regulation of suppressor of cellular signaling proteins by RNAi on glucose transport of intrauterine growth retardation rats. Pediatr Res 2011, 69(6):497-503.

29. Yang Z, Hulver M, McMillan RP, Cai L, Kershaw EE, Yu L, Xue B, Shi H: Regulation of insulin and leptin signaling by muscle suppressor of cytokine signaling 3 (SOCS3). PLoS One 2012, 7(10):e47493.

30. Tellechea ML, Steinhardt AP, Rodriguez G, Taverna MJ, Poskus E, Frechtel G Common variants in SOCS7 gene predict obesity, disturbances in lipid metabolism and insulin resistance. Nutr Metab Cardiovasc Dis 2013, 23(5):424-431.

31. Damcott CM, Pollin TI, Reinhart LJ, Ott SH, Shen H, Silver KD, Mitchell BD, Shuldiner AR: Polymorphisms in the transcription factor 7-like 2 (TCF7L2) gene are associated with type 2 diabetes in the Amish: replication and evidence for a role in both insulin secretion and insulin resistance. Diabetes 2006, 55(9):2654-2659.

32. Rampersaud E, Damcott CM, Fu M, Shen H, McArdle P, Shi X, Shelton J, Yin $J$, Chang YP, Ott SH, et al: Identification of novel candidate genes for type 
2 diabetes from a genome-wide association scan in the Old Order Amish: evidence for replication from diabetes-related quantitative traits and from independent populations. Diabetes 2007, 56(12):3053-3062.

33. Shuldiner AR, O'Connell JR, Bliden KP, Gandhi A, Ryan K, Horenstein RB,

Damcott CM, Pakyz R, Tantry US, Gibson Q, et al: Association of

cytochrome P450 2C19 genotype with the antiplatelet effect and clinical efficacy of clopidogrel therapy. JAMA 2009, 302(8):849-857.

doi:10.1186/1756-0500-6-235

Cite this article as: Capuano et al:: Polymorphisms in the SOCS7 gene

and glucose homeostasis traits. BMC Research Notes 2013 6:235.

\section{Submit your next manuscript to BioMed Central and take full advantage of:}

- Convenient online submission

- Thorough peer review

- No space constraints or color figure charges

- Immediate publication on acceptance

- Inclusion in PubMed, CAS, Scopus and Google Scholar

- Research which is freely available for redistribution 